\title{
Freqüência de irrigação por gotejamento durante o estádio vegetativo do tomateiro para processamento industrial
}

\author{
Waldir Aparecido Marouelli(1) e Washington Luiz de Carvalho e Silva(2)
}

(1)Embrapa Hortaliças, Caixa Postal 218, CEP 70359-970 Brasília, DF. E-mail: waldir@cnph.embrapa.br (2)Embrapa Sede, Parque Estação Biológica - PqEB s/no, CEP 70770-901 Brasília, DF. E-mail: washington.silva@embrapa.br

\begin{abstract}
Resumo - Objetivo deste trabalho foi o de estabelecer critério para o manejo de água, durante o estádio vegetativo do tomateiro para processamento industrial, nas condições de cerrado do Brasil Central. Foram avaliados seis turnos de rega entre 0,5 e 16 dias. $O$ estande final e a produtividade de frutos, maximizados em regas a cada 2 dias, apresentaram resposta quadrática com a freqüência de irrigação, enquanto a produção de biomassa foi maximizada em regas diárias. A massa média de fruto e o número de frutos por planta não foram influenciados pelos tratamentos; isto indica que as diferenças de produção foram causadas, principalmente, pela variação do estande final. A profundidade efetiva de raízes apresentou resposta linear positiva com o turno de rega. As plantas irrigadas a cada 8 e 16 dias apresentaram um sistema radicular cerca de $10 \mathrm{~cm}$ mais profundo do que aquelas irrigadas duas vezes por dia. O teor de sólidos solúveis totais, a acidez titulável e a taxa de fruto podre não foram influenciados pelos turnos de rega. Observou-se que para melhor desempenho do tomateiro, durante o estádio vegetativo as irrigações devem ser realizadas a cada 2 dias, ou seja, quando a tensão de água no solo atingir cerca de $17 \mathrm{kPa}$.
\end{abstract}

Termos para indexação: Lycopersicon sculentum, estresse hídrico, manejo da irrigação, turno de rega.

\section{Drip irrigation frequency for processing tomatoes during vegetative growth stage}

\begin{abstract}
The objective of this study was to establish a water management strategy for processing tomato vegetative growth stage, under "cerrado" conditions in the Central region of Brazil. Six irrigation interval treatments ranging from 0.5 to 16 days were evaluated. Plant final stand, biomass production, and fruit yield showed a quadratic response to irrigation interval, reaching a maximum for irrigation frequency of 2,1 , and 2 days, respectively. Average fruit mass and number of fruit per plant were not influenced by the irrigation intervals, suggesting that observed yield differences resulted from treatments effect on plant stand. Effective rooting depth increased linearly with irrigation frequency. Plants irrigated at 8 and 16 days intervals showed a rooting system about $10 \mathrm{~cm}$ deeper than those irrigated twice a day. Titratable acidity, total soluble solids content, and rotten fruit rate were not affected by irrigation frequency. For best tomato crop performance, irrigations during vegetative stage should be given at a 2-day frequency, which corresponds to a soil water tension of $17 \mathrm{kPa}$.
\end{abstract}

Index terms: Lycopersicon sculentum, water stress, irrigation scheduling, irrigation interval.

\section{Introdução}

No Brasil, não existem informações consistentes sobre o manejo adequado da irrigação por gotejamento, durante o estádio vegetativo do tomateiro para processamento industrial. Isto tem limitado, com alguma freqüência, o rendimento da cultura.

A irrigação por gotejamento em tomateiro, quando associada à prática da fertirrigação, pode proporcionar um incremento de produtividade e uma economia de água de até 30\%, em comparação aos demais sistemas de irrigação (Colla et al., 1999; Prieto et al., 1999).
Em relação à aspersão, método predominante na região do Cerrado de Goiás e Minas Gerais, o gotejamento possibilita aumento de $30 \%$ a $50 \%$ na eficiência do uso de água pelas plantas (Prieto et al., 1999). O gotejamento, por ter a água aplicada diretamente ao solo, sem molhar a folhagem e os frutos, contribui com a diminuição da incidência de doenças da parte aérea e do apodrecimento de frutos, e pode reduzir o uso de fungicidas em até $60 \%$ (Marouelli \& Silva, 2002). Tais vantagens têm feito a área de tomateiro irrigado por gotejamento aumentar, de forma consistente, nos últimos cinco anos; em 2004 foram 1.120 ha. Nos próximos 
anos, o incremento deverá ser ainda maior, haja vista que a maior indústria de processamento, localizada no território nacional, tem como meta que, em 2007, 50\% de toda a área de tomate contratada seja irrigada por gotejamento.

Na região do Cerrado, responsável por cerca de $80 \%$ da produção nacional de tomate para processamento, a irrigação por aspersão tem sido manejada de forma a promover déficit hídrico, durante o estádio vegetativo das plantas, como forma de maximizar a produtividade de frutos. Essa estratégia, além de reduzir o uso de água e energia, favorece maior crescimento radicular do tomateiro e diminui a ocorrência de doenças. Marouelli et al. (1991) verificaram que a incidência de doenças da parte aérea e o apodrecimento de frutos foram significativamente reduzidos, sem prejuízo da produtividade, quando as plantas foram submetidas a condições de déficit hídrico moderadamente alto $(460 \mathrm{kPa})$, durante o estádio vegetativo. Segundo os autores, tal fato se deve a dois fatores principais: maior arejamento no dossel das plantas, proporcionado pelo menor crescimento da parte aérea, durante o estádio vegetativo, e maior intervalo entre irrigações no estádio de frutificação, possibilitado pelo aprofundamento de raízes.

Vários produtores, que utilizam o sistema por gotejamento, têm seguido o critério de manejo recomendado para tomateiro irrigado por aspersão e adotado a estratégia de promover déficit hídrico durante o estádio vegetativo, com a adoção de turnos de rega entre 7 e 12 dias, visando permitir maior aprofundamento do sistema radicular das plantas, reduzir o uso de água e a incidência de doenças. Outros preferem irrigar em regime de alta freqüência (1 a 2 dias), sem provocar qualquer déficit hídrico às plantas, pois acreditam que tal estratégia favorece maiores rendimentos. Todavia, tais estratégias, não fundamentadas em resultados de pesquisas específicos para gotejamento, têm causado, com alguma freqüência, problemas como redução de estande, menor produtividade de frutos e maior incidência de doenças de solo, durante o estádio inicial da cultura, e da parte aérea ou do fruto, durante os estádios finais da cultura, o que pode ser constatado em nível de campo.

Marouelli et al. (2003b) verificaram para tomateiro irrigado por gotejamento, que a produtividade de frutos do híbrido Heinz 9498 foi otimizada, quando as irrigações foram realizadas para uma tensão matricial de $70 \mathrm{kPa}$, durante o estádio vegetativo, e de $15 \mathrm{kPa}$, durante a frutificação. A adoção de tal critério, para fins de manejo de água, envolve custos com a aquisição de sensores de umidade e uso de mão-de-obra para a leitura dos mesmos, além da adoção de freqüência de rega variável, o que desagrada à maioria dos agricultores. Para o usuário, é altamente desejável adotar turnos de rega fixos, visto que as práticas culturais e outras atividades, realizadas na propriedade, podem ser previamente planejadas. Recomendações para o manejo de água, com base em turno de rega, no entanto, devem ser determinadas para condições específicas, pois são altamente afetadas pelas condições climáticas e de solo (Prieto et al., 1999).

O objetivo deste estudo foi estabelecer a freqüência ótima de irrigação por gotejamento, durante o estádio vegetativo do tomateiro para processamento industrial, nas condições de cerrado do Brasil Central, com o fim de otimizar a produtividade e qualidade de frutos.

\section{Material e Métodos}

O experimento foi conduzido em 2001, no campo experimental da Embrapa Hortaliças, em Brasília, DF, a $15^{\circ} 56^{\prime} \mathrm{S}, 48^{\circ} 8^{\prime} \mathrm{W}$ e altitude de $997 \mathrm{~m}$. A região possui clima tropical de altitude, do tipo Cwa, conforme classificação de Köppen, e solo do tipo Latossolo Vermelho distrófico, fase cerrado e textura argilosa. A retenção de água no solo (\%vol.), entre 0 e $20 \mathrm{~cm}$ de profundidade, no intervalo de tensão $\left(\Psi_{\mathrm{m}}\right)$ de 5 a $1.500 \mathrm{kPa}$, foi ajustada à equação de van Genuchten, produzindo a seguinte relação:

$\theta\left(\Psi_{\mathrm{m}}\right)=23,0+14,8 /\left[1+\left(0,057 \times \Psi_{\mathrm{m}}\right)^{1,743}\right]^{0,429}$

Os tratamentos aplicados durante o estádio vegetativo do tomateiro consistiram de seis turnos de rega: 0,5 (duas irrigações por dia), 1, 2, 4, 8 e 16 dias. O estádio vegetativo correspondeu ao período entre o estabelecimento inicial das plantas e o início da frutificação, ou seja, entre o 6o e o 370 dias após o transplante das mudas. A parcela experimental foi de $28,8 \mathrm{~m}^{2}$, com quatro linhas de plantas de $6 \mathrm{~m}$. O delineamento experimental utilizado foi blocos ao acaso, com quatro repetições.

O transplante das mudas do híbrido AP533, produzidas em bandejas de isopor de 288 células, foi realizado tardiamente, na terceira semana de junho, para evitar chuvas no período dos tratamentos, no espaçamento de $30 \times 120 \mathrm{~cm}$. O solo foi previamente irrigado, elevandose o conteúdo de água à capacidade de campo na camada até $40 \mathrm{~cm}$. A adubação foi realizada com $200 \mathrm{~kg}$ de $\mathrm{N}, 300 \mathrm{~kg}$ de $\mathrm{K}_{2} \mathrm{O}, 600 \mathrm{~kg}$ de $\mathrm{P}_{2} \mathrm{O}_{5}, 160 \mathrm{~kg}$ de $\mathrm{Ca}$, $40 \mathrm{~kg}$ de $\mathrm{Mg}, 5 \mathrm{~kg}$ de $\mathrm{Zn}$ e $2 \mathrm{~kg}$ de B por hectare, tendo 
sido utilizadas as seguintes fontes: uréia, nitrato de potássio, nitrato de cálcio, nitrato de duplo potássio, cloreto de potássio, cloreto de cálcio, superfosfato simples, cal hidratada, sulfato de magnésio, sulfato de zinco e bórax. Todo o fósforo, os micronutrientes, $15 \%$ do nitrogênio e do potássio e $70 \%$ do cálcio foram fornecidos em préplantio, e o restante, de forma parcelada via fertirrigação.

As irrigações foram realizadas por meio de uma linha lateral de gotejadores, com vazão de $1,2 \mathrm{~L} \mathrm{~h}^{-1}$, espaçados em $30 \mathrm{~cm}$. Para minimizar a formação de uma zona de saturação, junto ao colo da planta, a linha lateral foi posicionada de $5 \mathrm{a} 10 \mathrm{~cm}$ em relação à de plantas.

Para garantir um desenvolvimento uniforme das plântulas, as irrigações foram efetuadas diariamente em todos os tratamentos, nos primeiros cinco dias após o transplante. A partir desse momento, até o início da frutificação, os turnos de rega foram diferenciados conforme cada tratamento. Durante os estádios de frutificação e de maturação, adotou-se uma freqüência de 1 e 3 dias, respectivamente, e as irrigações foram paralisadas quando a taxa de maturação de frutos atingiu cerca de $50 \%$.

A lâmina de água aplicada nos tratamentos, com turno de rega de 0,5 e 1 dia, foi determinada a partir da evaporação do tanque Classe A e coeficientes de cultura reportados por Marouelli \& Silva (2002). Os dados de evaporação, assim como outros dados climáticos, foram obtidos de uma estação meteorológica situada cerca de $500 \mathrm{~m}$ da área experimental.

Nos demais tratamentos, a lâmina foi determinada com base no esgotamento de água no solo (Keller \& Bliesner, 1990), considerando-se uma fração de área molhada de 0,35 e uma profundidade efetiva de raízes de $20 \mathrm{~cm}$. O conteúdo de água no solo, para os tratamentos com turno de rega de 2 e 4 dias, foi determinado pela equação ajustada de van Genuchten, a partir de leituras tensiométricas, enquanto naqueles com turno de rega de 8 e 16 dias foi determinado por gravimetria. Os tensiômetros foram instalados, e as amostras de solo coletadas, a cerca de $10 \mathrm{~cm}$ da planta e do gotejador, e a $10 \mathrm{~cm}$ de profundidade, em plantas posicionadas a $10 \mathrm{~cm}$ do gotejador. Para evitar o pisoteio das plantas nas parcelas experimentais, as determinações de tensão e umidade no solo foram realizadas antes de cada irrigação, nos tratamentos com freqüência de 4 a 16 dias, e a cada quatro dias, nos demais tratamentos.

As condições climáticas médias reinantes durante o estádio vegetativo do tomateiro foram: temperatura do ar de $22,3{ }^{\circ} \mathrm{C}$, umidade relativa do ar de $55,3 \%$, insolação de 9,4 horas, radiação global de $18,6 \mathrm{MJ} \mathrm{m}^{-2} \mathrm{dia}^{-1}$, velocidade do vento de $1,1 \mathrm{~m} \mathrm{~s}^{-1}$, e evaporação do tan- que classe A de $6,9 \mathrm{~mm} \mathrm{dia}^{-1}$. Pelo método do tanque, a evapotranspiração de referência foi estimada em $5,5 \mathrm{~mm} \mathrm{dia}^{-1}$. Do transplante de mudas até o término dos tratamentos não houve ocorrência de chuvas; a partir daí, foram registrados $240 \mathrm{~mm}$ de precipitação.

A colheita dos frutos foi realizada manualmente em uma única operação. As variáveis avaliadas foram: estande final, biomassa, frutos maduros, produtividade de frutos, massa média de fruto, número de frutos por planta, frutos podres e maduros, acidez titulável, sólidos solúveis totais e profundidade efetiva de raízes. A biomassa foi determinada secando-se a parte aérea das plantas a $60^{\circ} \mathrm{C}$, excluindo-se todos os frutos. A concentração de frutos maduros foi determinada pela relação entre a massa de frutos maduros e totais, excluindo-se os podres. Para produtividade, massa média de fruto e número de frutos por planta foram considerados apenas aqueles maduros, sem danos, independentemente de tamanho. A acidez titulável e o teor de sólidos solúveis totais foram determinados conforme Moretti et al. (1998), em amostras de quinze frutos por parcela.

A profundidade efetiva do sistema radicular, com cerca de $80 \%$ das raízes, foi determinada pelo método do perfil reticulado, com duas repetições, seguindo-se metodologia descrita por Atkinson \& Mackie-Dawson (1991). Foi utilizada uma malha de $5 \times 5 \mathrm{~cm}$, até uma profundidade de $110 \mathrm{~cm}$, procedendo-se à contagem do número de interseções das raízes com as linhas da malha, e à posterior estimativa do comprimento total de raízes dentro de cada malha.

Os dados das variáveis avaliadas foram submetidos à análise de variância, e aquelas afetadas pelos tratamentos foram analisadas com regressão linear, pelo método de polinômios ortogonais (Montgomery, 1991). Para haver ortogonalidade entre os tratamentos, usouse a transformação logarítmica dos turnos de rega.

\section{Resultados e Discussão}

A lâmina líquida total de água aplicada via irrigação, ao longo do ciclo do tomateiro, nos diferentes tratamentos, variou de 230 a $293 \mathrm{~mm}$, e o menor valor foi obtido no tratamento com turno de rega de 16 dias (Figura 1). Desses totais, $40 \mathrm{~mm}$ foram aplicados antes do início dos tratamentos, incluindo a irrigação de pré-transplante, e $168 \mathrm{~mm}$ após o término dos tratamentos.

Os valores médios de tensão de água do solo, antes de cada irrigação, durante o estádio vegetativo, para os turnos de rega de $0,5,1,2,4,8$ e 16 dias foram, respectivamente, de $6,10,17,32,60$ e $120 \mathrm{kPa}$, e isso indica que as plantas foram submetidas a uma ampla faixa de regime hídrico (Figura 1). 
A colheita dos frutos, em todos os tratamentos, foi realizada aos 108 dias após o transplante das mudas. A concentração de frutos maduros, média de $92,3 \%$, em massa, não foi afetada significativamente $(p>0,05)$ pelos turnos de rega avaliados. Portanto, a ocorrência de déficit hídrico, durante o estádio vegetativo do tomateiro, dentro da faixa estudada, não teve efeito na duração do ciclo das plantas. Comportamento semelhante foi verificado em estudo realizado por Prieto et al. (1999).

A profundidade efetiva do sistema radicular do tomateiro, avaliada após a colheita, apresentou resposta linear positiva com o turno de rega (Figura 2), o que indica que plantas submetidas a um maior déficit de água no solo, durante o estádio vegetativo, apresentam raízes mais profundas do que aquelas irrigadas mais freqüentemente. Além de possibilitar um melhor aproveitamento dos nutrientes presentes no solo, plantas com sistema radicular mais profundo possibilitam uso de maiores turnos de rega durante o estádio de frutificação (Sanders et al., 1989; Keller \& Bliesner, 1990), o que reduz a incidência de doenças e o apodrecimento de frutos (Lopes \& Santos, 1994).

O estande final de plantas apresentou resposta quadrática aos turnos de rega aplicados durante o estádio vegetativo (Figura 2); o maior número de plantas por unidade de área $\left(2,9\right.$ plantas $\left.\mathrm{m}^{-2}\right)$ ocorreu para um turno de rega de 2 dias. Principalmente para freqüências acima de 8 dias, houve uma expressiva redução de estande, em conseqüência do maior estresse hídrico a que as plantas foram submetidas, ou seja, tensões de até $120 \mathrm{kPa}$. Algumas plantas podem ter sido submetidas a tensões ainda maiores, pois enquanto as plantas em que as tensões foram avaliadas estavam a cerca de

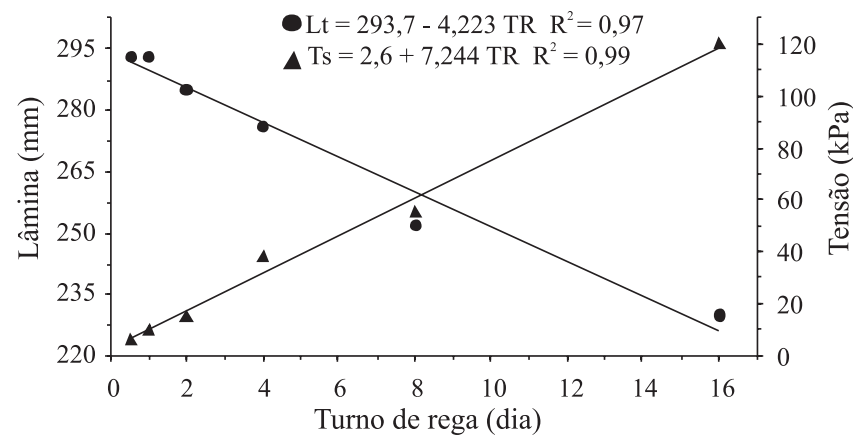

Figura 1. Lâmina líquida total de irrigação, ao longo do ciclo do tomateiro ( $\mathrm{Lt}$ ), e tensão média de água no solo, antes de cada irrigação, durante o estádio vegetativo (Ts) do tomateiro, em função do turno de rega (TR) utilizado.
$10 \mathrm{~cm}$ dos gotejadores, outras podiam estar a até $20 \mathrm{~cm}$. Isso ocorreu por causa das variações, de certa forma aleatórias, no espaçamento entre plantas, ocorrido durante a operação de transplante de mudas, e entre a linha de gotejadores e a de plantas.

A redução de estande em tratamentos irrigados em regime de alta freqüência (duas vezes por dia) se deu, provavelmente, por causa de doenças de solo favorecidas pela manutenção de alto teor de água próximo ao colo das plantas (Lopes \& Santos, 1994).

A produção de biomassa, avaliada pela massa seca da parte aérea sem os frutos, foi maximizada para um turno de rega de 1 dia (Figura 3). Quando as irrigações foram realizadas com intervalo de 16 dias, ocorreu uma redução na biomassa de $38 \%$ em relação à máxima, o que se deve à maior redução de estande, bem como a um menor crescimento das plantas. Colla et al. (1999) verificaram que plantas submetidas à deficiência hídrica moderada ( $20 \%$ de redução da lâmina de água) não tiveram o crescimento reduzido de forma significativa. Tais divergências devem-se principalmente ao fato de que as plantas, no presente estudo, foram submetidas a condições de deficiência hídrica apenas durante o estádio vegetativo, e que a redução na lâmina de água aplicada entre tratamentos foi superior a 20\% (Figura 1).

Observa-se, pela função de resposta quadrática ajustada, que a maior produtividade de frutos foi obtida para um turno de rega de 2 dias (Figura 3). O menor rendimento foi verificado para o turno de rega de 16 dias, com uma redução de $20 \%$ em relação à freqüência que maximizou a produção. Pela análise do intervalo de confiança de $95 \%$ dos parâmetros do modelo ajustado (constante $= \pm 2,380$; termo linear $= \pm 3,383$; termo quadrático $= \pm 1,463$ ), a máxima resposta produtiva do tomateiro

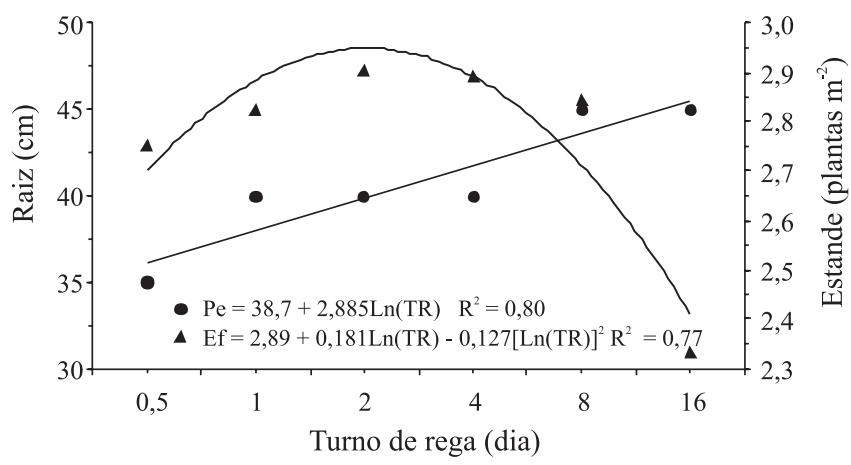

Figura 2. Profundidade efetiva do sistema radicular $(\mathrm{Pe})$ e estande final de plantas (Ef), em função do turno de rega (TR) utilizado durante o estádio vegetativo do tomateiro. 
não diferiu, significativamente, para turnos de rega entre 1 e 5 dias.

Pelos resultados obtidos, ao contrário do preconizado por muitos produtores, o maior crescimento radicular, associado à estratégia de manejo de submeter as plantas a condições de déficit de água no solo, durante o estádio vegetativo, não foi traduzido em ganho de produção de frutos por unidade de área ou por planta. Portanto, tal estratégia, recomendada e utilizada com sucesso na irrigação por aspersão, por reduzir a incidência de doenças da parte aérea (Marouelli et al., 1991), não se mostrou vantajosa em termos de produtividade de frutos, provavelmente porque o problema de doenças da parte aérea não é crítico no sistema de irrigação por gotejamento e, também, porque parte dos nutrientes foi aplicada semanalmente via fertirrigação.

A massa de fruto, média de $75,5 \mathrm{~g}$, e o número de frutos por planta, média de 37,8 , não foram afetados estatisticamente $(p>0,05)$ pelos tratamentos de irrigação. Tais resultados permitem dizer que as diferenças de produtividade observadas ocorreram, predominantemente, pelo efeito dos tratamentos sobre o estande de plantas. Em tomateiro irrigado por aspersão, Marouelli et al. (1991) verificaram que o déficit hídrico, durante o estádio vegetativo, também não teve efeito significativo sobre a massa de fruto, mas reduziu o número de frutos por planta. A razão para tal divergência pode ser a diferença entre os sistemas de irrigação. Na aspersão, o maior crescimento da parte aérea, no estádio vegetativo, favorece o apodrecimento de frutos e, naquele estudo, as plantas foram submetidas a condições de maior estresse hídrico no solo (460 kPa).

Nenhuma das variáveis de qualidade de fruto avaliada foi afetada, significativamente ( $p>0,05)$, pelos trata-

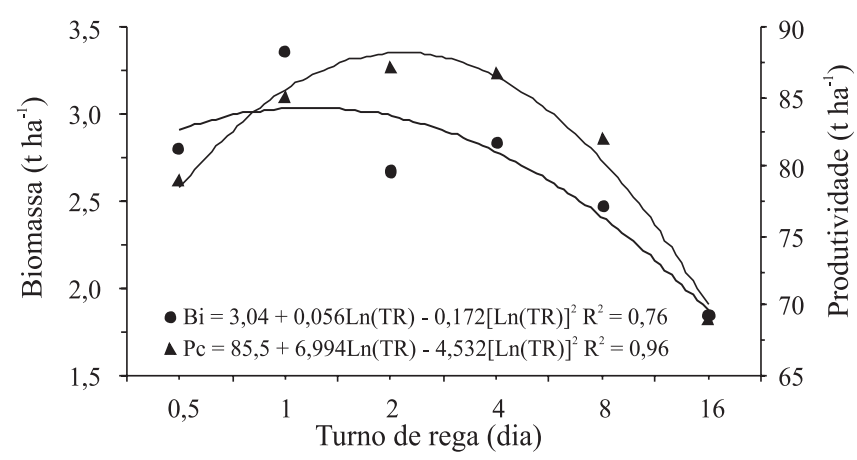

Figura 3. Produção de biomassa (Bi) e produtividade de frutos $(\mathrm{Pc})$, em função do turno de rega (TR) utilizado durante o estádio vegetativo do tomateiro. mentos. A acidez titulável média foi de $0,31 \%$ de ácido cítrico, e o teor de sólidos solúveis totais foi de 3,2\%. O baixo teor de sólidos solúveis se deu, em grande parte, pela ocorrência de $158 \mathrm{~mm}$ de chuva durante o estádio de maturação, período crítico para a concentração de sólidos (Lowengart-Aycicege et al., 1999). A alta ocorrência de chuvas, no final do ciclo do tomateiro, também foi responsável pela alta taxa de frutos podres (média de 9,9\%, em número) e baixa produtividade (69 a $87 \mathrm{t} \mathrm{ha}^{-1}$ ) observadas em todos os tratamentos. Frutos com podridão apical tiveram ocorrência inferior a $0,1 \%$. $\mathrm{O}$ efeito não significativo sobre as variáveis de qualidade era de se esperar, uma vez que os tratamentos de irrigação foram aplicados, exclusivamente, durante o estádio vegetativo do tomateiro, portanto, antes do efetivo desenvolvimento dos frutos.

\section{Conclusões}

1. Plantas submetidas a um maior déficit de água no solo, durante o estádio vegetativo, apresentam uma profundidade efetiva do sistema radicular maior do que aquelas irrigadas em regime de mais alta freqüência.

2. A maior produtividade de frutos está associada à adoção de um turno de rega de 2 dias, ao longo do estádio vegetativo, que corresponde, para o solo em questão, a uma tensão de água do solo para reinício das irrigações de $17 \mathrm{kPa}$.

3. O decréscimo de produtividade de frutos, sob condições de estresse hídrico, especialmente durante o início do estádio vegetativo do tomateiro, está associado, principalmente, à redução do estande de plantas.

4. A acidez titulável e o teor de sólidos solúveis totais não são influenciados pelos regimes hídricos adotados durante o estádio vegetativo.

\section{Agradecimentos}

À Rain Bird do Brasil Ltda., pela doação de parte do sistema de irrigação; à Unilever BestFoods do Brasil Ltda., pelo fornecimento das mudas de tomateiro.

\section{Referências}

ATKINSON, D.; MACKIE-DAWSON, L.A. Root growth: methods of measurement. In: SMITH, K.A.; MULLINS, C.E. Soil analysis. New York: Marcel Dekker, 1999. p.447-509.

COLLA, G.; CASA, R.; LO CASCIO, B.; SACCARDO, F.; TEMPERINI, O.; LEONI, C. Responses of processing tomato to water regime and fertilization in central Italy. Acta Horticulturae, v.487, p.531-535, 1999. 
KELLER, J.; BLIESNER, R.D. Sprinkler and trickle irrigation. New York: VanNostrand Reinhold, 1990. 652p.

LOPES, C.A.; SANTOS, J.R.M. Doenças do tomateiro. Brasília: EMBRAPA/SPI, 1994. 67p.

LOWENGART-AYCICEGI, A.; MANOR, H.; KRIEGER, R.; GERA, G. Effects of irrigation scheduling on drip-irrigated processing tomatoes. Acta Horticulturae, v.487, p.513-518, 1999.

MAROUELLI, W.A.; SANT'ANA, R.R.; SILVA, W.L.C.; MORETTI, C.L.; VILELA, N.J. Avaliação técnica e econômica do espaçamento de gotejadores em tomateiro para processamento industrial cultivado em fileiras simples e duplas. Horticultura Brasileira, v.21, p.202-206. 2003a.

MAROUELLI, W.A.; SILVA, H.R.; OLIVEIRA, C.A.S. Produção de tomate industrial sob diferentes regimes de umidade no solo. Pesquisa Agropecuária Brasileira, v.26, p.1531-1537, 1991.

MAROUELli, W.A.; SILVA, W.L.C. Tomateiro para processamento industrial: irrigação e fertirrigação por gotejamento. Brasília: Embrapa Hortaliças, 2002. 32p. (Embrapa Hortaliças. Circular Técnica, 30).
MAROUELLI, W.A.; SILVA, W.L.C.; MORETTI, C.L. Resposta do tomateiro para processamento industrial à tensões de água no solo, sob irrigação por gotejamento. Engenharia Agrícola, v.23, p.1-8, 2003b.

MONTGOMERY, D.C. Design and analysis of experiments. 3.ed. New York: John Wiley \& Sons, 1991. 649p.

MORETTI, C.L.; SARGENT, S.A.; HUBER, D.J.; CALBO, A.G.; PUSCHMANN, R. Chemical composition and physical properties of pericarp, locule and placental tissues of tomatoes with internal bruising. Journal of the American Society for Horticultural Science, v.123, p.656-660, 1998.

PRIETO, M.H.; LÓPEZ, J.; BALLESTEROS, R. Influence of irrigation system and strategy of the agronomic and quality parameters of the processing tomatoes in Extremadura. Acta Horticulturae, v.487, p.575-579, 1999.

SANDERS, D.C.; HOWELL, T.A.; HILE, M.M.S.; HODGES, L.; PHENE, C. Tomato root development affected by traveling trickle irrigation rate. Hortscience, v.24, p.930-936, 1989.

Recebido em 29 de abril de 2004 e aprovado em 22 de fevereiro de 2005 